\title{
VIOLENCIA PROTAGÓNICA EN LA CIUDAD Y LOS PERROS (1963) DE MARIO VARGAS LLOSA: ENFOQUES NARRATOLÓGICO Y SEMIÓTICO*
}

\author{
Protagonic violence in The city and the dogs (1963) by Mario Vargas \\ Llosa: narratological and semiotic approaches
}

\author{
Jesús Miguel Delgado Del Aguila**
}

\section{RESUMEN}

El personaje violento resulta ser un quebrantador de leyes sociales y órdenes establecidos, además de que intenta determinarse como un protagonista y un héroe con esa rebeldía. Estos planteamientos, aunque son erróneos, se deben a que la formación obtenida por este individuo es algo empobrecedora: tiene baja tolerancia a la frustración y las expresiones inadecuadas de rabia, posee cierta carencia o una deficitaria red de apoyo social; y, peor aún, al concebirse como vencedor, puede poner a prueba su dominio por castigar al conquistado, hasta incluso lo hace llegar a su aniquilación (rasgo muy importante para explicar la muerte del Esclavo). Por medio de la tríada protagónica (el Jaguar, el Poeta y el Esclavo), los personajes atraviesan por una serie de transformaciones ontológicas que permite ver las actitudes y los comportamientos condicionados por el factor de la violencia. Para ello, se usará la semiótica empleada por Landowski, Desiderio Blanco y Fontanille.

Palabras clave: violencia, semiótica, análisis literario, programas narrativos, regímenes de sentido.

\begin{abstract}
The violent turns out to be a breaker of social laws and established orders, in addition to trying to determine himself as a protagonist and a hero with that rebellion. These approaches, although erroneous, are due to the fact that the training obtained by this individual is somewhat impoverishing: he has low tolerance to frustration and inadequate expressions of anger, he has a certain lack or a deficient social support network; and, worse still, when he conceives himself as the victor, he can put his mastery to the test by punishing the conquered, until he even reaches his annihilation (a very important feature to explain the death of the Slave). Through the protagonist triad (the Jaguar, the Poet and the Slave), the characters go through a series of ontological transformations that allow to see the attitudes and behaviors conditioned by the factor of violence. For this, the semiotics used by Landowski, Desiderio Blanco and Fontanille will be used.
\end{abstract}

Key Words: violence, semiotics, literary analysis, narrative programs, regimes of meaning.

\footnotetext{
* El siguiente artículo forma parte de mi tesis de licenciatura, titulada Protagonismo violento y modos de representación en La ciudad y los perros (1963), financiada por la Universidad Nacional Mayor de San Marcos (Lima-Perú), a través del Fondo de Promoción de Trabajo de Tesis de Pregrado (2012) del VRI-UNMSM. La última versión se terminó de elaborar en el 2017.
}

*** Docente de la Universidad Tecnológica del Perú. Lima, Perú. Orcid: 0000-0002-2633-8101. Correo electrónico: tarmangani2088@outlook.com

Recepción: 06-02-2018. Aceptación: 27-02-2018. 


\section{Introducción}

Para la construcción del personaje, es recomendable, paralelamente, el diseño de otros recursos narrativos. Gérard Genette (1998, p. 94) propone la noción de que la caracterización es la técnica de construcción del personaje a través del texto narrativo; por lo que el diseño de los mismos es más importante que el de la construcción histórica. Tomando en cuenta estas pautas, se trataría de reconocer que ambos recursos son impredecibles: el del personaje mismo -caracterizado mayormente por su conducta violenta- y el de la historia -que en este caso estaría marcada por secuencias con las que la violencia se representa-. Por esta razón, se desarrollará en este apartado cuáles serían las características del personaje violento, qué importancia tendría para él la toma de poder, en qué sentido admite el ideal del Otro en su formación y cómo es que la víctima se construye bajo su percepción.

En primer lugar, para hacer alusión a las características, Hernández Granda (2001, p. 23) señala que la forma de conducta violenta se distingue por ser una reacción al peligro (real o supuesto) que, a la vez, genera la disminución del propio poder-obsérvese de qué manera actúa el Jaguar cuando sus compañeros lo toman por soplón, él ya presiente que dejará de ser el líder y que el único modo de corregir esa humillación será golpeándolos a todos-. Esta, a su vez, se dirigiría a personas u objetos, pero, secundariamente, se podría volver contra uno mismo cuando él se siente obstaculizado por resistencias externas o reprimido por imperativos sociales con proyección a la adaptación social; por ejemplo, lo que el Jaguar provoca al pelearse contra toda su sección es confirmar su propuesta de que él los ha transformado a todos, se han convertido en él mismo y, por lo tanto, no dejarán que ya nadie los domine.

La conducta violenta puede manifestarse de múltiples maneras, entre las cuales se incluye la crueldad, la discusión, la desobediencia, las exigencias, los cambios de humor, las peleas, las amenazas o el acoso a otros; en consecuencia, podríamos considerar también en tales términos el maltrato de carácter racista o xenófobo (el hecho de emplear palabras como "serrano" o "negro" indican que hay una necesidad de inferiorizar al otro mediante un rasgo étnico natural). Lacan (2006, p. 23) afirma que, cuando no se desarrolla el "juego", suscita la cólera. Este concepto se asocia bastante con el de agresión, maltrato, violencia y abuso, los cuales no son excluyentes para explicar esa anomalía conductual. El maltrato queda descrito con palabras como sometimiento, humillación, dominio, 
miedo o esclavitud; mientras que la agresión sería toda lesión provocada. Es abuso cualquier comportamiento encaminado a controlar y subyugar a otro ser humano mediante el recurso del miedo y la humillación; para ello, se vale de ataques físicos o verbales.

El personaje violento entiende su equilibrio emocional como control absoluto del otro, es por eso que sabe a quién puede tomar de víctima -como cuando el Jaguar hace que el Esclavo lo remplace en su función de imaginaria-; tiene, generalmente, antecedentes de violencia en su familia de origen, con el peligro de que repita su conducta violenta en las sucesivas relaciones que mantenga con otras personas, sobre todo si son mujeres -recuérdese lo que hace el Jaguar con un chico que estaba junto a Teresa en la playa, quien resultó gravemente lastimado, por celos-; además, siempre pedirá una segunda oportunidad -el Jaguar retorna luego de tiempo para estar con Teresa y casarse con ella, a pesar de haber tenido una ruptura a causa de su propio carácter agresivo-.

Lubomir Doležel (1999, p. 162) señala que es importante también ver la frecuencia del conflicto -entre las personas, los grupos y los estados-, ya que esta ha llevado a algunos psicólogos a derivar o no controlar el impulso de la violencia, con consecuencias totalmente fatales. Se tiene ya por costumbre, en el Colegio Militar Leoncio Prado, recibir con golpes, insultos y humillaciones a los alumnos que recién ingresan a convivir en aquel espacio. Los que son apodados "los perros" sufrirán las terribles humillaciones en el llamado "bautizo", en el que todo está permitido; es más, las autoridades estimularán aquella acción violenta con su propio retiro para obviar el suceso. Al permitir y aceptar estas actitudes, se incentiva a que la violencia esté perenne en aquel ámbito; es una buena justificación para que en cualquier momento se tengan comportamientos similares con estos alumnos. La violencia se expresaría en la actitud crítica, el interés en el poder, la exigencia y el dominio; y se visualizaría de un modo más portentoso al pensarse que la ironía se sobrepondría (como si se tratara de una representación humorística de los hechos que contrarresta la manifestación de la ira). Una persona colérica asume los acontecimientos de forma seria y, con ello, genera una pérdida de aprehensión de asuntos que son realmente importantes; de igual manera reaccionará el iracundo, quien no tiene sentido del humor, ni siquiera para las actividades domésticas. Mario Perniola (2008, pp. 42-43) indica algo similar al sostener que el adversario ideológico - al aludir al personaje violento en este caso- podría ser tratado también como 
una bestia: se le niega su condición humana, se le despoja de su individualidad con la dimensión social y es objeto de todo tipo de escarnio.

Al respecto, Eva Hernández Granda (2001, p. 22) encuentra dos tipos de aspectos que detectarían a un individuo violento: los emocionales y los cognitivos. Dentro de los aspectos emocionales, podrían apreciarse el enojo, el fastidio, el disgusto, la envidia, la codicia, el deseo, los celos, la censura, entre otros derivados. En cambio, si se refiere a los aspectos cognitivos, se hallan los siguientes patrones: mayor eficacia de la racionalidad -el Jaguar sabe que no podrá aprobar el examen de Química, por ello, planea un robo; asimismo, está cuando deduce que el Esclavo fue quien delató al serrano Cavay el autocontrol -el Jaguar tiene conocimiento de que puede pegarle a cualquiera; por eso, cuando el Poeta le reta a pelearse, no se resiste, debido a que asume que le ganará-. Se encuentran también otros factores importantes, como la sustitución, la sublimación, la competencia -el Jaguar se retaría a sí mismo al luchar solo contra los alumnos de quinto, el desarrollo, la agresividad verbal, la empatía -tanto así que el Jaguar logra formar el Círculo bajo su supervisión- y la sensibilidad social.

Otras maneras de encontrar actitudes violentas son por medio de manifestaciones conductuales, ya sean por medio de la agresividad verbal y gestual. Por ejemplo, problemas de disciplina (como el de insultar a los profesores o murmurar de alguna autoridad), conductas disruptivas, insultos, deserción de proyectos y actitudes contrarias a estos, comportamiento prosocial y destructivo, peleas, maltrato a compañeros (agresiones, extorsiones, etc.), vandalismo, daños materiales (centro o material de compañeros), acoso y agresión sexual. Graciela Ferreira sostiene que el hombre violento puede aparentar ser un sujeto de bien; es más, puede alcanzar una reputación académica y profesional sorprendente, como un ciudadano modelo: no se le podrá distinguir fácilmente. Muchos especialistas concuerdan en afirmar que la gran mayoría de los agresores no posee patologías psiquiátricas, por lo que confirmaría la propuesta anterior. Aquello ya sería visible en el Jaguar cuando deja el Colegio Militar; es decir, al casarse y convertirse en una persona trabajadora, puesto que, aparentemente, no se sabría bajo qué patrones está moldeada su conducta, por más que represente un cariz óptimo. Y no solo sería la visión empática que brindaría a los ciudadanos, también existe una normalidad en el trato con la mujer -tal como lo señala Sigmund Freud (2004, p. 347) al decir que los perversos se comportan, por lo menos, con respecto a su objeto sexual, aproximadamente del mismo modo que los normales en función del suyo; entendiendo 
como objeto sexual a la mujer, no habría déficits al llevar una relación amorosa sin que la violencia se incluya, a pesar de que el mismo sujeto violento está dentro de la dinámica. El Jaguar nunca lastimó a Teresa, más bien la educó, la instruyó, la hizo sentirse importante, sin tener en cuenta su condición humana y económica.

En segundo lugar, es importante determinar la concepción de toma de poder, pues Jiddu Krishnamurti (1991, p. 71) acata que la violencia es inseparable de la existencia del ser humano, ya que se funda en el yo y es su egocentrismo el que se encarga de complementarla. A la vez, esta surge del ser humano al aceptar cierta incapacidad personal, la hace propia; y, debido a ella, es que se siente confiado de sí mismo (de igual manera que si este individuo no cometiera injusticias; pero, si las padeciera, sentiría ira). Entonces, el núcleo esencial del poder es la violencia -para este caso, comparemos al Jaguar con el Esclavo: el primero no tiene problemas para acercarse a conversar con una chica; en cambio, el segundo necesita de intermediarios, cartas, ilusiones y otras tantas artimañas para estar al tanto de lo que le sucede en torno a su amor platónico, Teresa-. Es la violencia la que les ha brindado valor y confianza a los personajes; mas, no es todo. Habría una intención de ser más capaz que otros tantos, una búsqueda de una victoria simbólica: la adquisición del poder. Este se ejerce por la represión (impedimento a la persona subordinada que realiza acciones voluntarias). Esta actitud provoca un reordenamiento de la constelación de agentes y la transforma en una jerarquía asimétrica. Doležel (1999, p. 156) encuentra tres tipos de poder, dependiendo de la fuente: el poder físico (por armas o fuerza corporal), el mental (por medio de destrezas y conocimientos) y el social (en grupos organizados, como las formas institucionales, junto con las jerarquías políticas, militares o corporativas). Estas relaciones de poder son factores motivadores generales, aplicables a las interacciones persona-persona, persona-grupo y grupo-grupo.

En tercer lugar, se observa al violento como si se tratase de otro; se entiende por este, según Lacan (1996, p. 70), la representación de una entidad imaginaria que sirve para evidenciar algunas deficiencias del sujeto, como también, aludir a las relaciones de mando y dominancia. Para él, el Otro es quien tiene cuerpo y, a la vez, no existe. Es un ideal impuesto por el hombre mismo, que cuenta con la función de hacer creer que se trata de una entidad completa, con la que el individuo pretende representarse en su totalidad. 
En La ciudad y los perros, el imperativo sería que quien es el más violento es el que se acerca a esa figura del Otro: utopía a la que aspiran los personajes que habitan en el Colegio Militar Leoncio Prado. Para Lacan (1996, p. 64), los individuos no gozan de deseos propios, pues es el Otro quien les enseña a desear; por lo tanto, sus anhelos solo llegan a ser réplicas de la configuración ontológica de ese Otro. Este será quien alcance a ser el modelo por antonomasia, porque se presenta como aval del lenguaje y es sometido a toda su dialéctica: él tiene la razón y a él se le debe seguir -caso similar a lo que Slavoj Žižek (2008, p. 19) llamaría el gran Otro: Dios, quien tendría el sumo poder sobre los demás humanos-.

En la novela, el Jaguar sería el modelo más próximo del violento, por lo que tratarían de imitarlo de alguna u otra forma, ya sea el indicio que pueda captar el alumno (una conducta, un gesto, una risa, una broma, etc.); el Esclavo es quien se percata de ello y se lo manifiesta al Poeta en una conversación: "Y tú imitas la risa del Jaguar" (Vargas Llosa, 2012, p. 25); más adelante, Alberto le responde lo siguiente: “Es verdad [...]. Me estoy riendo como el Jaguar. ¿Por qué lo imitan todos?” (Vargas Llosa, 2012, p. 26). Mas, no solo es lo externo lo que induciría a pensar que se trata de copiar a ese Otro. Debajo de este, se encontraría el sitio donde se produce la pérdida: la huida del plus del goce. ¿El impacto que reciben los presentes al ver una actitud violenta en el Jaguar es similar al del Poeta? El Jaguar preferiría más veces contar con mayor experiencia en función de la forma de vida en la calle y continuar generando admiración y buenas expectativas en sus amistades de ese entorno - como lo hace frente al flaco Higueras-, que comportarse insensiblemente en el colegio, donde sus compañeros son menos fuertes y violentos que él. El Colegio Militar Leoncio Prado no le causa un mayor impacto, más bien, se trataría tan solo de algo irrelevante. Al respecto, Jacques Lacan (Žižek, 2004, p. 115) señala que el perverso sabe perfectamente lo que es: un saber sostiene su posición como objeto del goce del Otro (del sujeto dividido); el refrán "tú me pegas" genera esa división del sujeto, el hecho de pensar que, por más que se haga lo que se haga, existirá un modelo superior al que se pretende alcanzar. Y, al final, esta fórmula que constituye el vínculo con el goce, solo significaría el propio goce que se genera el Otro. A fin de cuentas, el Jaguar no termina contento: existe en él un afán de seguir imponiendo su conducta constantemente. Sus goces espontáneos que se genera para sí mismo no resultan ser diacrónicos: no se satisface. 
En cuarto lugar, la presencia de la víctima es fundamental para analizar las repercusiones generadas por el agresor. Victoria Sau (Álvarez, 2002, p. 16) precisa que la obra perfecta de la agresividad es conseguir que la víctima admire al verdugo. ¿El Esclavo lo hace? Ante ello, esa necesidad de admiración es solo utópica, ya que el ofendido se subordina por temor al acosador; cada persona buscaría en sus propias acciones encontrar un soporte de goce, ¿el sometimiento sería propio de ser halagado?, ¿provoca felicidad? En consecuencia, el Jaguar tendría la falsa idea de que sus compañeros lo respetan, pero al final se revela que no es así, porque la cantidad de rebeldes con respecto a su persona provoca que se genere una fuerza mayor a la de él; por lo tanto, se disipará el miedo que le poseían. Al enfrentársele varios, es dudoso hallar a un solo culpable luego de la acometida, el Jaguar no podrá vengarse esta vez: antes, tendrá que pelear nuevamente contra toda su sección y ganarle si es que quiere conseguir, en esa oportunidad, esa sensación de temor que les había creado a todos en función de su persona.

\section{El protagonista y el personaje. Propuestas narratológicas y semióticas}

Para Mijaíl M. Bajtín (1998, pp. 201-209), el protagonista es la entidad que busca su destino (resultados reales), además de ponerse en constantes pruebas (sobre todo, axiológicas). Este tipo de personaje será producto de la interacción entre el concepto de héroe y autor, ya que el primero está sometido al segundo, como rol pasivo al que se le instala una actitud determinada y estructurada del mejor modo estético y sincrético. La manera con la que se revele la conducta del protagonista será mediante la impresión que él genere al exteriorizar sus estados internos, como cuando el Jaguar delata su personalidad al luchar contra los alumnos de quinto año y derrotarlos (la pelea se clasificaría como factor externo; y lo interno sería la violencia, como también, el rechazo a la injusticia). El protagonista se muestra en la vida con sus respectivas formas positivas y negativas, dependiendo de cómo le ha ayudado la colectividad (la familia, la moral, la educación o la religión) a constituir su personalidad determinista, libre e individual. Si la función protagónica se enfoca por la adquisición del bien, esta será tomada como un sujeto -término empleado por Paul Ricoeur (1995, p. 465) para determinar a un personaje de buenas intenciones-; allí se ubicarían al Poeta y el Esclavo, quienes, al final de tantos problemas, deciden denunciar los abusos manifestados en el interior del Colegio Militar Leoncio Prado; mientras que si se tratara de un protagonista que practica el mal, se le 
denominaría antisujeto, porque impide el desarrollo normal de la historia novelada, al colocárselo como un obstáculo y una amenaza -el Jaguar estaría dentro de esta clasificación, puesto que es un personaje principal que se encarga de difundir la violencia-.

Para clasificar el rol protagónico desde el enfoque semiótico, se requiere la regularización narratológica a partir de actantes que revelan ciertas actitudes cambiantes. Fontanille (2001, p. 125) define al actante como aquella entidad abstracta que cuenta con un compromiso funcional para la predicación narrativa; este puede ser transformacional, cuando tiene una intencionalidad de participar en la escena predicativa del enunciado.

La tradición semiótica distingue dos clases de modificaciones: la primera, perteneciente al sujeto y el objeto en su relación con el deseo y la búsqueda; y la segunda, la que depende de la comunicación, que asocia al destinador y el destinatario. Puede tratarse también de actantes posicionales, como la mira, la cual está guiada por la intencionalidad; la captación, que circunscribe el espacio puesto en la mira; la fuente, al vincularse al actante que se pone en la mira y capta; y el blanco, que es la entidad semiótica puesta en la mira y captada.

Donde mayor se apreciaría el rol de los actantes en La ciudad y los perros, sería al emplear los programas narrativos y el esquema de la prueba, por los que el protagonista se implicaría al mostrarnos sus constantes variaciones.

\subsection{Los programas narrativos}

Fontanille (2001, p. 169) precisa que todo programa narrativo consiste en ver cómo los sujetos logran transformaciones a partir de uniones o separaciones de objetos (estos pueden ser físicos, abstractos o tratarse de un sujeto). Esta afirmación revela que los personajes no son planos por las constantes alteraciones o modificaciones de conductas que atraviesan por medio de desembragues (disyunción que permite el tránsito de la posición original a otros estadios) y embragues (conjunción que se encarga de volver al estado primario); por ello, se trataría de personajes redondos, debido a que cambian a lo largo de la historia. Asimismo, los programas narrativos se clasifican en conjuntivos y disyuntivos. Un programa narrativo es conjuntivo cuando un objeto es adquirido por un 
sujeto; por ejemplo, si se toma la violencia como un objeto y al Jaguar como un sujeto, se tendrían las siguientes valencias:

\section{S: el Jaguar \\ O: la violencia}

En una instancia de la novela, el protagonista adquirirá este valor simbólico violento para derrotar a los alumnos de quinto año, al ser recién un ingresante, y adquirir con ello cierto respeto y la alteración de los órdenes establecidos. El gráfico que se hace en un programa conjuntivo es el siguiente: $(\mathrm{S} \vee \mathrm{O}) \rightarrow(\mathrm{S} \Lambda \mathrm{O})$. En este, se aprecia cómo el sujeto, en un estado, primero se desvinculaba con el objeto, para que después logre adquirirlo por medio de la violencia. También, puede graficarse de otra forma; será allí donde se aprecie el tránsito de la disyunción a la conjunción adoptado por el sujeto.

$$
\mathrm{S} 1 \rightarrow(\mathrm{S} 2 \mathrm{~V} \mathrm{O}) \rightarrow(\mathrm{S} 2 \Lambda \mathrm{O})
$$

De esa manera, los sujetos y el objeto tienen los siguientes valores:

S1: el Jaguar, quebrantador de tradiciones e imposiciones

S2: el Jaguar, ingresante, visto como inofensivo

$$
\text { O: respeto }
$$

Cuando se trata de un programa disyuntivo, el recorrido es el inverso: $(\mathrm{S} \Lambda \mathrm{O}) \rightarrow$ (S V O). Un ejemplo sería cuando matan al Esclavo, el mejor amigo del Poeta, ya que con este se aprecia la separación amical y única de aquel vínculo que caracterizaba a ambos personajes dentro del Colegio Militar. El Poeta sería el sujeto y la amistad, el objeto.

$$
\begin{aligned}
& \text { S: el Poeta } \\
& \text { O: amistad }
\end{aligned}
$$

El otro modo de graficar un programa narrativo disyuntivo sería viendo el tránsito de la conjunción a la disyunción (de la unión a la separación).

$$
\mathrm{S} 4 \rightarrow(\mathrm{S} 5 \Lambda \mathrm{O}) \rightarrow(\mathrm{S} 5 \mathrm{~V} \mathrm{O})
$$

Los valores inferidos en los sujetos y el objeto serían los siguientes: 
S4: el Poeta, conformado con la vida militar al tener un amigo

S5: el Poeta, desolado, angustiado y con necesidad de hacer justicia

O: la amistad

\subsection{El esquema de la prueba}

Fontanille señala que este esquema atraviesa por el recorrido de la confrontación, la dominación y la apropiación o la desposesión.

confrontación $\rightarrow$ dominación $\rightarrow$ apropiación/desposesión

En ella, se intenta decidir, según la motivación de cada sujeto (Doležel, 1999, p. 102), la elección, la intensidad y la persistencia de las actividades. Una escena resaltante en la que se observa todo este proceso es cuando el Poeta y el Jaguar pelean en la celda del Colegio Leoncio Prado. Estos dos sujetos toman su respectiva posición en el mismo campo discursivo. Por lo tanto, el esquema de la prueba se construiría a partir de los siguientes enunciados:

debate $\rightarrow$ pelea entre el Jaguar y el Poeta $\rightarrow$ respeto/injusticia

* La confrontación, configurada como el debate verbal que se genera entre ambos protagonistas por un desacuerdo (“¿quién mató al Esclavo?”), consiste en la exposición de dos actantes y sus respectivos programas (el Jaguar: cinismo vs. el Poeta: reclamo).

* La dominación, en este caso, la asume la violencia, puesto que depende de ella que ambos personajes disputen físicamente. Con la pelea, recién se logrará la oportunidad de que el Jaguar y el Poeta compitan en fuerza, pues el hecho de que alguien sepa pelear más no significa que asegure su victoria: todo dependerá del azar. Los sujetos comparan sus habilidades físicas y se enfrentan para saber quién sacará ventaja en función del otro.

* La apropiación/desposesión se construye en el binomio de respeto/injusticia. Según Fontanille (2001, p. 99), la apropiación consistiría en el programa narrativo de conjunción que beneficia al vencedor (el Jaguar adquiriría cierto respeto sobre el Poeta, debido a que, al derrotarlo, le está demostrando que no puede hacer nada contra su configuración de asesino infiltrado); mientras que la desposesión es definida por Fontanille como el programa narrativo de disyunción, el cual lo padece el otro sujeto (el 
Poeta, al resultar derrotado, no asciende una posición de violencia que permitiría distinguir al Jaguar como más débil ni tampoco logra vengar la muerte del Esclavo; resulta todo lo contrario: es golpeado y chantajeado después por las autoridades militares).

\section{Los planos de la expresión y el contenido}

Umberto Eco (2000, p. 22) fundamentaba que la semiótica es la disciplina que estudia todo aquello que puede usarse para mentir o hacer referencia a la inscripción de conceptos en un universo de sentido, los cuales son descifrados en el texto por medio de la semiosis o la semiotización. El análisis parte de la presencia de un cuerpo propio, el cual ofrece dos vertientes, según Desiderio Blanco (2003, p. 63): el exteriorizado, que recepciona los estímulos sensibles del mundo explícito (expresiones y sensaciones); y el interiorizado, que recibe los estímulos sensibles del mundo implícito (contenido: emociones y afectos).

\section{Cuerpo propio $=$ C. $\mathrm{P} .=$ plano de la expresión (exteroceptivo)

$$
\text { plano del contenido (interoceptivo) }
$$

Una vez constituidas correctamente las partes que conforman un cuerpo propio, se intentará buscar una significación. Esta, que se genera por medio del análisis y la interpretación, surge de una configuración preconcebida: se toman modelos o tipos que representan paradigmas identificables por el sujeto; de allí, se buscará entrecruzar lo sensible con lo inteligible -tal como indica Desiderio Blanco (2009, pp. 16-17)-, para mostrarnos los valores que corresponden a una determinada expresión. Si colocamos un ejemplo de la novela de Vargas Llosa, podemos identificar la función que poseen dos espacios textualizados; por ejemplo, si nos referimos al Colegio Militar Leoncio Prado, aludimos a la intención que tiene la institución de contrarrestar la imperfección de la nueva sociedad por medio de instrucciones violentas; mientras que, si colocamos a la sociedad limeña en el plano de la expresión, podemos hallar en su contenido la afección por la que atraviesa a causa del tercermundismo. Por lo tanto, el gráfico sería el siguiente:

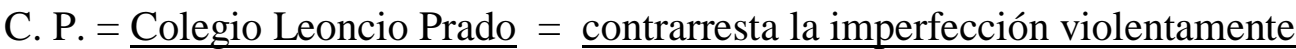


Dentro de la semiótica, no solo hallamos este proceso significativo entre el hallazgo de los valores de los planos de la expresión y el contenido, también, se puede recurrir al sistema simbólico, el cual ayuda a encontrar significados más profundos de aquellos referentes analizados. La correlación semisimbólica entre los planos del contenido (estado de ánimo) y la expresión (efecto de una determinada toma de posición sobre el mundo) produce una significación particular, en la que la dimensión interoceptiva resulta preeminente y muy destacable respecto a la dimensión exteroceptiva. Además de eso, Fontanille (2001, p. 116) añade que el sistema semisimbólico se establece en distintas etapas, en las que se supone que existe una organización cosmológica de modo cultural. Por ejemplo, si analizamos la tríada protagónica, le atribuiríamos los siguientes valores:

Jaguar: violento / Poeta: camaleónico / Esclavo: calmado

Con ello, se indica que esta configuración propioceptiva se ha hecho a partir de la sociedad degradada que plantea La ciudad y los perros; pero, si se pretende hallar los semisimbolismos, bastará encontrar un significado más extenso en los contenidos derivados de esas tres expresiones (la tríada protagónica: el Jaguar, el Poeta y el Esclavo). Por lo tanto, para especificar aún más, en torno al depósito cultural de los sujetos, se deduce lo siguiente:

violento: sin cultura / camaleónico: mediocre / calmado: aplicado

Luego, se afirma que ser violento significa estar sin cultura, sin que eso sea una proyección interpretativa personal: la red de relaciones que se articula allí está totalmente controlada por los actos de discurso. Mas, el análisis de este sistema semisimbólico no es el único; de esos valores, también se reconoce lo siguiente:

sin cultura: amenaza / mediocre: sobreviviente / aplicado: destruido

Estos dos sistemas semisimbólicos referidos, que son transitivos, podrían sintetizarse en las identidades que adoptan los personajes mencionados, ya que ellos obtienen calificaciones inmediatas hechas en el proceso significativo de la propioceptividad. En conclusión, se derivaría lo siguiente:

* Jaguar: violento : sin cultura : amenaza

* Poeta: camaleónico : mediocre : sobreviviente

* Esclavo: calmado : aplicado : destruido 


\section{El cuadrado semiótico}

Paul Ricoeur se enfoca en las operaciones lógicas del cuadrado semiótico para organizar la narración en cuanto proceso creador de valores.

Según Fontanille (2001, p. 51), el cuadrado semiótico se manifiesta como la conjunción de los dos tipos de oposiciones binarias en un solo sistema, que administra, a la vez, la presencia simultánea de rasgos contrarios, como también, su presencia y su ausencia.

En este caso, se tratará de aplicar este postulado semiótico en la tríada protagónica violenta; para ello, me valdré de la clasificación provisional que se le hará a partir de los regímenes de sentido (programación, ajuste, accidente y manipulación) y los modos de existencia (virtual, actualizado, potencializado y realizado).

\subsection{Los regímenes de sentido}

Landowski señalaba cuatro regímenes de sentido importantes: la programación, el ajuste, el accidente y la manipulación.

Primero, la programación (Landowski, 2009, p. 30) permite al sujeto interactuar con regularidad; al mismo tiempo, busca la transformación de los estados $(\mathrm{S} \rightarrow \mathrm{O})$ en un objeto o un sujeto tomado como objeto. Para que esta entidad sea programable, por parte de un sujeto, es necesario que cumpla con su rol temático o esté programada; entonces, inmediatamente, se cumplirá en ella el "hacer ser" con respecto al individuo. Este régimen puede apreciarse en los roles que cumplen los principales responsables de la violencia en el ámbito militar; por ejemplo, el Jaguar, al ser el líder del Círculo, tiene la función de realizar acciones inmorales constantemente (para ello, se vale del desenvolvimiento de su violencia).

Segundo, para Landowski (2009, p. 48), el ajuste es la capacidad de sentirse recíprocamente o hacerse conjunto. Se manifiesta en el cambio topográfico y la inclusión de nuevos parámetros (no antes experimentados en la sensibilidad del personaje), lo que lo conducirá al accidente de manera resistida. Este modo de regir la forma de actuar se aprecia destacablemente en Alberto Fernández, a causa de que él está acostumbrado a una vida acomodada, con interrelaciones sociales de gente miraflorina (que no recurre a la 
violencia para tratar con los demás), aunque tendrá que ajustarse a una conducta semiviolenta al momento de ingresar en el Colegio Militar (emplea groserías, molesta, actúa con violencia y pelea cuando es necesario).

Tercero, el accidente (Landowski, 2009, p. 71) se ocasionaría cuando un proceso de programación, manipulación o ajuste saliera mal. Del ejemplo anterior, el Poeta fracasaría al no saber llevar un modo de vida dual (con la práctica del bien fuera del colegio y la de lo seudomalo en el Leoncio Prado), puesto que ocurre una digresión en su existencia: es chantajeado por las autoridades militares y se arriesga a ser expulsado del colegio, motivos por los cuales tendrá que cambiar su forma de actitud y regirse directamente a las exigencias que le dictan otros.

Cuarto, el régimen de la manipulación tiende al principio de intencionalidad: busca inmiscuirse en la vida interior de otro, y trata de influir en sus motivos para que actúe en un sentido determinado. El Jaguar es un manipulador representativo, debido a que él dirige a la mayoría de la sección del colegio (tiene a su cargo el Círculo y los cadetes respetan sus decisiones). En una ocasión, genera que el Esclavo haga guardia por él (lo que revela que el Jaguar tuvo las artimañas violentas suficientes para deshacerse de un rol que no le gustaba, para otorgárselo a otro).

Cuando estos cuatro regímenes de sentido se insertan en un cuadrado semiótico, tendrían el siguiente recorrido (el cual se cumple en La ciudad y los perros):

\section{PROGRAMACIÓN}

$$
(+)
$$

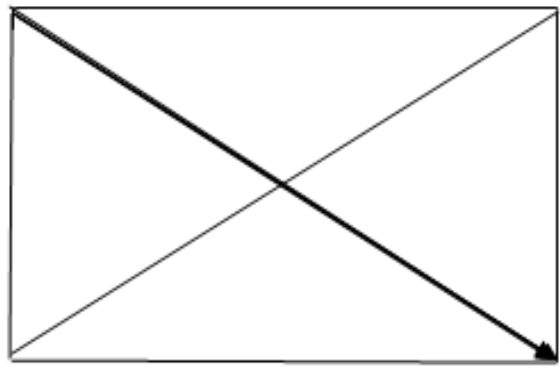

\section{MANIPULACIÓN}

\section{ACCIDENTE}

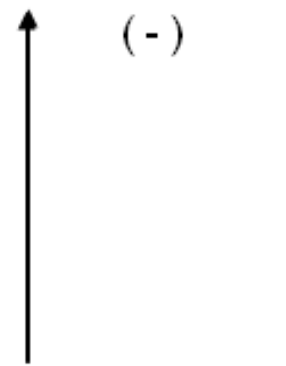

AJUSTE

(?)

El recorrido que parte de la programación, el ajuste y el accidente es notorio en las transformaciones ontológicas que padecen los protagonistas principales. En el caso del Jaguar, se programa y se ajusta como sujeto violento; sin embargo, recurre al accidente cuando se culpabiliza por haber abusado de la violencia de modo extremo al 
asesinar al Esclavo; esto permite que se destruya su identidad construida y reconfigure su vida posteriormente. Lo mismo sucede con los otros dos personajes. Con el Poeta, su programación y su ajuste se basan en saber sobrevivir en el Colegio Militar, considerando su honor; pero es conducido por el accidente al ser chantajeado por las autoridades militares (quienes le han puesto una limitación: no actuar con libertad, es decir, no denunciar al responsable de la muerte de Ricardo Arana). Finalmente, el Esclavo se programa como una entidad sumisa y pasiva en el ámbito militar violento del Leoncio Prado, mas no podrá ajustarse de manera correcta cuando esté privado de su libertad para salir del colegio; el accidente ocurre al denunciar al serrano Cava, ya que esta acción le correspondía a alguien que pudiera valerse por sí mismo, porque, en caso de alguna emboscada, él podría detener cualquier tipo de invectiva. Asimismo, añado que este accidente es el peor de todos los apreciados en la novela, debido a que no puede regenerarse al personaje de ninguna forma: ha sido asesinado.

\subsection{Los modos de existencia}

Fontanille (2001, p. 238) plantea que los modos de existencia (el virtualizado, el actualizado, el potencializado y el realizado) convierten, de alguna forma, esta presencia intuitiva en un espesor discursivo: proyectan articulaciones modales en función del campo del discurso. Estos se distribuyen de la siguiente manera:

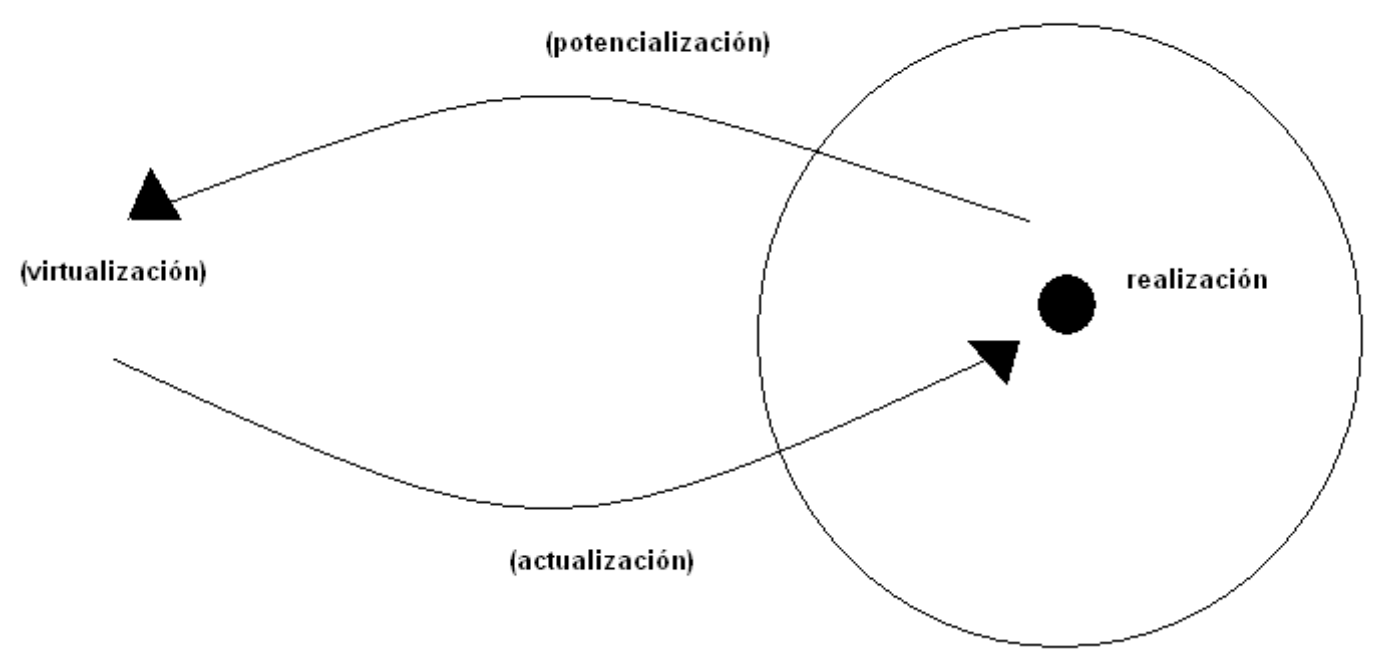


En primer lugar, el modo virtual es aquel que se halla fuera del campo del discurso y apto para cualquier tipo de producción de sentido. Este comprende todas las formas posibles del lenguaje, la sensibilidad y la percepción. Se deja regir por lo alético (lo posible) y se visualiza en la novela cuando los protagonistas van construyendo su identidad conforme transcurre el tiempo (quien pretenda configurar su identidad violenta sabrá que para alcanzarla deberá infundir terror a los demás, aparte de luchar contra todo aquel que intente tomar el poder).

En segundo lugar, el modo actualizado comprende los hechos y las formas realizados del discurso, que se rigen de la acción y la transformación de los estados de las cosas. Esta modalidad revela el pasaje de la frontera por medio de las modalidades factuales (querer, saber, poder y hacer). En La ciudad y los perros, este cambio de parecer se generaría por una razón: el hecho de estar ya en el Colegio Militar Leoncio Prado implicará una modificación de actitud para sobrevivir.

En tercer lugar, el modo potencializado es aquel que se deja regir por las modalidades deónticas (Fontanille, 2001, p. 59) (el deber, la ley, la regla y los usos que programan la existencia y sus transformaciones). Se trataría en la novela por la educación militar que reciben los alumnos, sin excepción alguna (ellos estarán preparados para pelear).

En cuarto lugar, el modo realizado es el centro del campo del discurso, ya que genera que la enunciación haga que las formas del discurso se encuentren con una realidad: realidad material en los planos de la expresión (mundo natural) y el contenido (mundo sensible). Puede señalarse que esta modalidad se cumple cuando ya se tiene una configuración de los protagonistas al presenciar sus distintos actos y sus diferentes tipos de representación. El Jaguar connota violencia; el Poeta, una semiviolencia encubierta; y el Esclavo, una pasividad en torno a la acción.

Estos cuatro modos de existencia definidos son distribuidos por Desiderio Blanco (2009, p. 268) en un cuadrado semiótico con la siguiente organización: 


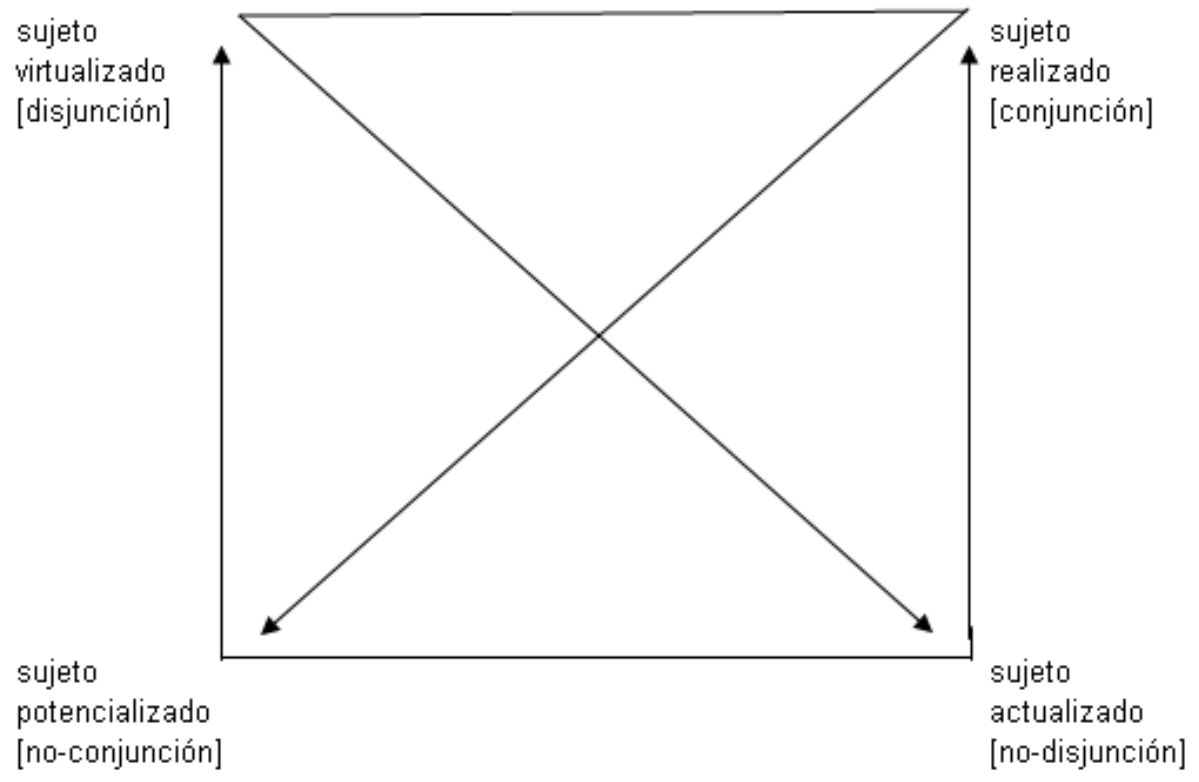

Fontanille (2001, pp. 239-240) distingue dos maneras de recorrer aquel cuadrado semiótico en relación con los modos de existencia: el ascendente y el descendente. El primero se realiza de acuerdo con las formas significantes, que son convocadas para su próxima manifestación. Este recorrido es analizable en dos actos diferentes.

- La fase virtualizado-actualizado $[\mathrm{V} \rightarrow \mathrm{A}]:$ representa la emergencia de una manera, además de ser una frase de innovación; este requisito lo obtienen los tres protagonistas: el Jaguar, al querer imponer su perfil violento y temerario, derrotará a los alumnos del quinto año cuando ellos pretendan "bautizarlo"; el Poeta, al enfocarse en sobrevivir de un modo adecuado en ese colegio, sin ser humillado ni agredir tanto a los demás cadetes; el Esclavo, al presenciar demasiada violencia en el Colegio Militar, recurre a esta fase cuando se distancia de toda manifestación agresiva e intolerable.

- La fase actualizado-realizado [A $\rightarrow \mathrm{R}$ ]: describe la aparición de una forma; esta recibe ahí una expresión y un estatuto de realidad que le permite hacer referencia. En la novela, esta representación se detecta por el Esclavo y el Poeta al saber que existe una necesidad de ser violento para poder convivir en el Colegio Militar, donde se pone como ejemplo al Jaguar, tal como lo identifica el Esclavo: "Es verdad — dice-. Me estoy riendo como el Jaguar. ¿Por qué lo imitan todos?” (Vargas Llosa, 2012, p. 26). El Jaguar, en cambio, sigue un modelo violento que le está generando la representación del flaco Higueras en función de sus vivencias callejeras. 
El segundo recorrido, el descendente, genera que los modos significantes queden implícitos - estos se guardan en la memoria, son tipificados, borrados u olvidados-. También, se distingue por dos fases.

- La fase realizado-potencializado $[\mathrm{R} \rightarrow \mathrm{P}]$ : es la condición del declive de una forma en cuanto se considera viviente e innovante; por lo tanto, describe su incorporación en el uso y se encuentra apta para otras convocaciones. Se manifiesta en los tres protagonistas al ingresar en el Colegio Militar, donde tendrán que desligarse completamente de su ingenuidad para aprehender los nuevos modos de vida violenta que deberán adoptar (son limitados por muchos factores: la fuerza, la edad, la experiencia violenta, etc.). Cualquiera no podrá ser violento y líder de otros cadetes ni será tan fácil tampoco ser un camaleón entre tantos alumnos; lo más fácil consistirá en ser una víctima y no luchar para sobrevivir -suceso que le ocurre al Esclavo-.

- La fase potencializado-virtualizado $[\mathrm{P} \rightarrow \mathrm{V}]$ : describe la desaparición de una forma y su disolución en las estructuras virtuales, subyacentes al ejercicio de una práctica significante. Este descenso o este abandono de una identidad ya configurada se percibe en los tres protagonistas. En el Jaguar, cuando retoma su vida ética, luego de haber asesinado al Esclavo y confesado su culpa al teniente Gamboa. El Poeta desiste de su identidad camaleónica al terminar su ciclo escolar, sobre todo, desde que se percata de que en su colegio se rigen por parámetros injustos e hipócritas. El Esclavo también abandona momentáneamente su posición al ver que todos no quieren revelar al culpable del robo del examen de Química, a pesar de que lo saben; el hecho de que acuse implica ya una rebeldía hacia su postura de enajenado, impotente y víctima.

\section{El esquema de tensiones}

Según Fontanille (2001, p. 62), los esquemas de tensiones se configuran a partir de la correlación entre las dimensiones de la intensidad -lo interno o lo interoceptivo que se convierte en el plano del contenido- y la extensión -lo externo o lo exteroceptivo que se transforma en el plano de la expresión-; estos dos ejes de control demarcan una representación de un cuerpo propio en particular (una presencia sensible, propioceptiva). Para poder ubicar y caracterizar lo propioceptivo, es necesario ver algunas maneras que permitirían distinguir una presencia de otra; por eso, Fontanille (2001, pp. 93-94) ha 
propuesto cuatro esquemas tensivos, en los que se adecúan los distintos modos de evidenciar la posición adquirida de un cuerpo propio.

\subsection{El esquema descendente o de decadencia}

Se manifiesta cuando la disminución de la intensidad, conjugada con el despliegue de la extensión, procura un reposo cognitivo.

\subsection{El esquema de la ascendencia}

Se percibe al existir un aumento en la intensidad, complementado con la reducción de la extensión: esto permite la proporción de una tensión afectiva.

\subsection{El esquema de la amplificación}

Se asocia con el aumento de la intensidad y el despliegue de la extensión; asimismo, se procura una tensión afectivo-cognitiva.

\subsection{El esquema de la atenuación}

Se caracteriza por la disminución de la intensidad, conjugada con la reducción de la extensión, la cual proporciona una inacción general.

En la novela de Vargas Llosa, la violencia es un incentivo que permite la exposición de las intenciones particulares de los protagonistas. Mas, unos actúan de manera distinta de otros; por lo tanto, predomina una serie de variaciones que rápidamente se ubicarían en algunos de los esquemas tensivos propuestos. Para este caso, pueden construirse dos esquemas de tensión que sintetizarían las principales actitudes abordadas en función o separación de la violencia.

El primer esquema de tensión se conformaría por el recorrido de los personajes, sobre la base de la violencia (desde un punto inicial, en el que creen que el Colegio Militar Leoncio Prado es un centro donde se puede vivir con la práctica del bien; hasta el final, 
en el que se piensa que el más fuerte o el violento manda y ordena al resto). Para el desarrollo de este esquema, destaco a la tríada protagónica en relación con su desenvolvimiento en aquel colegio, y priorizo al Jaguar (quien logra ese tránsito) y el Poeta (quien desea llegar a esa ventajosa posición).

\section{\begin{tabular}{|c|}
\hline ESQUEMA DE TENSIÓN DE LA AMPLIFICACIÓN: \\
INSERCIÓN DE LA VIOLENCIA EN EL COLEGIO MILITAR LEONCIO \\
\hline
\end{tabular}}

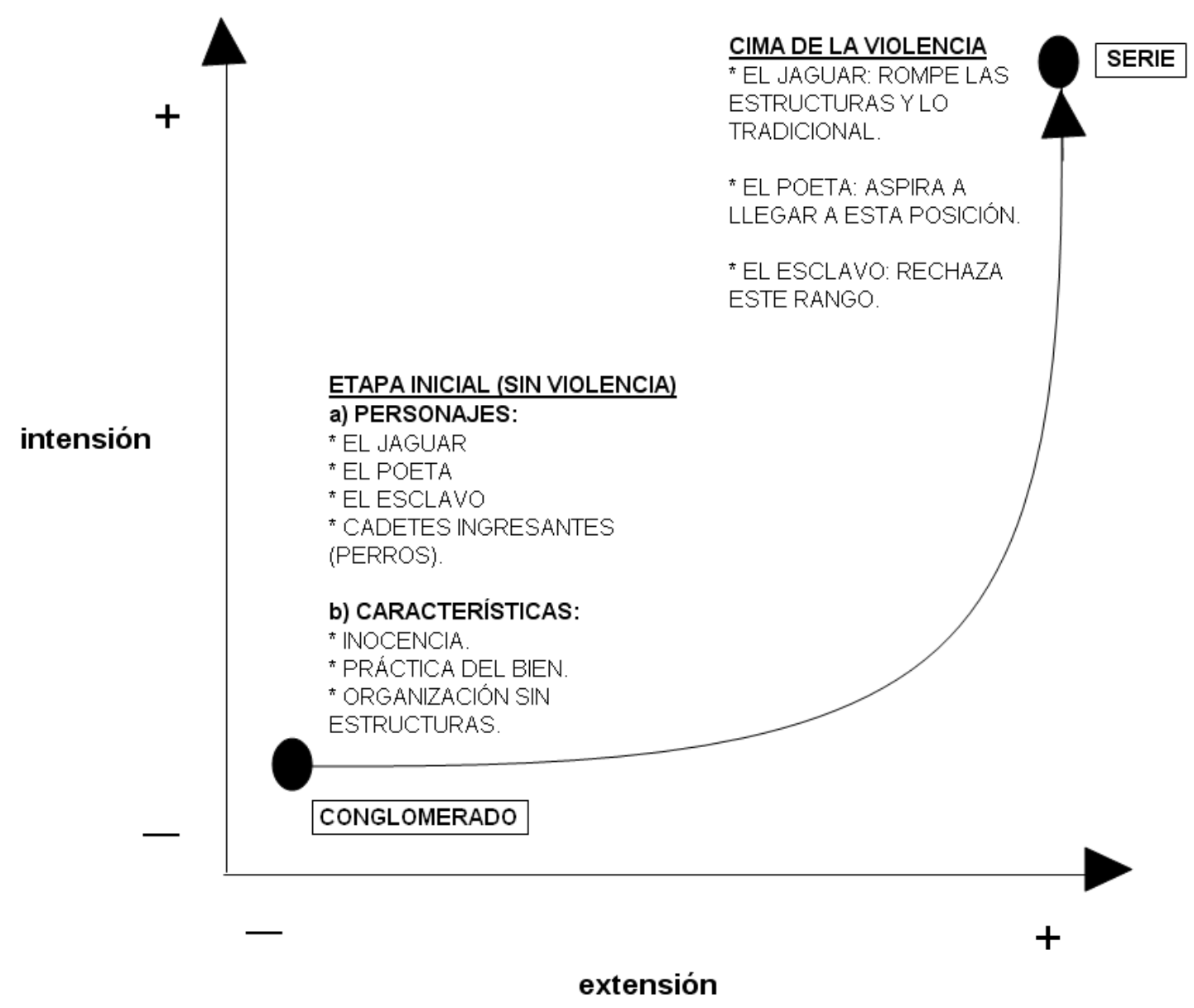

El esquema que corresponde a este gráfico es el de la amplificación (Blanco, 2009, p. 45), el cual consiste en el aumento de la intensidad, correlacionado con el despliegue de la extensión. Este esquema anhela los valores de apogeo y plenitud; se halla en función de todas las utopías y atraviesa por las zonas o los estilos categoriales (Blanco, 2009, p. 22) del conglomerado (intensidad y extensión débiles, que exponen, a la vez, ciertos rangos comunes) al de la serie (intensidad y extensión fuertes, particularidades de una base neutra). Como se observa en el gráfico, hay una necesidad de instaurar en el 
individuo un depósito de agresión para adquirir una conducta ideal y sobresalir del resto de cadetes al ser violento.

El segundo esquema de tensión estaría asociado con la lucha de la violencia y la ética. En este caso, será tan solo el Jaguar quien experimente este recorrido que, únicamente, se observa al final de la novela -al considerar que la violencia tan solo engendraría más violencia, a la vez que su resistencia generaría otras formas de distorsión, el cambio de actitud del Jaguar reinstalaría una nueva organización en las conductas evolutivas de los sujetos-.

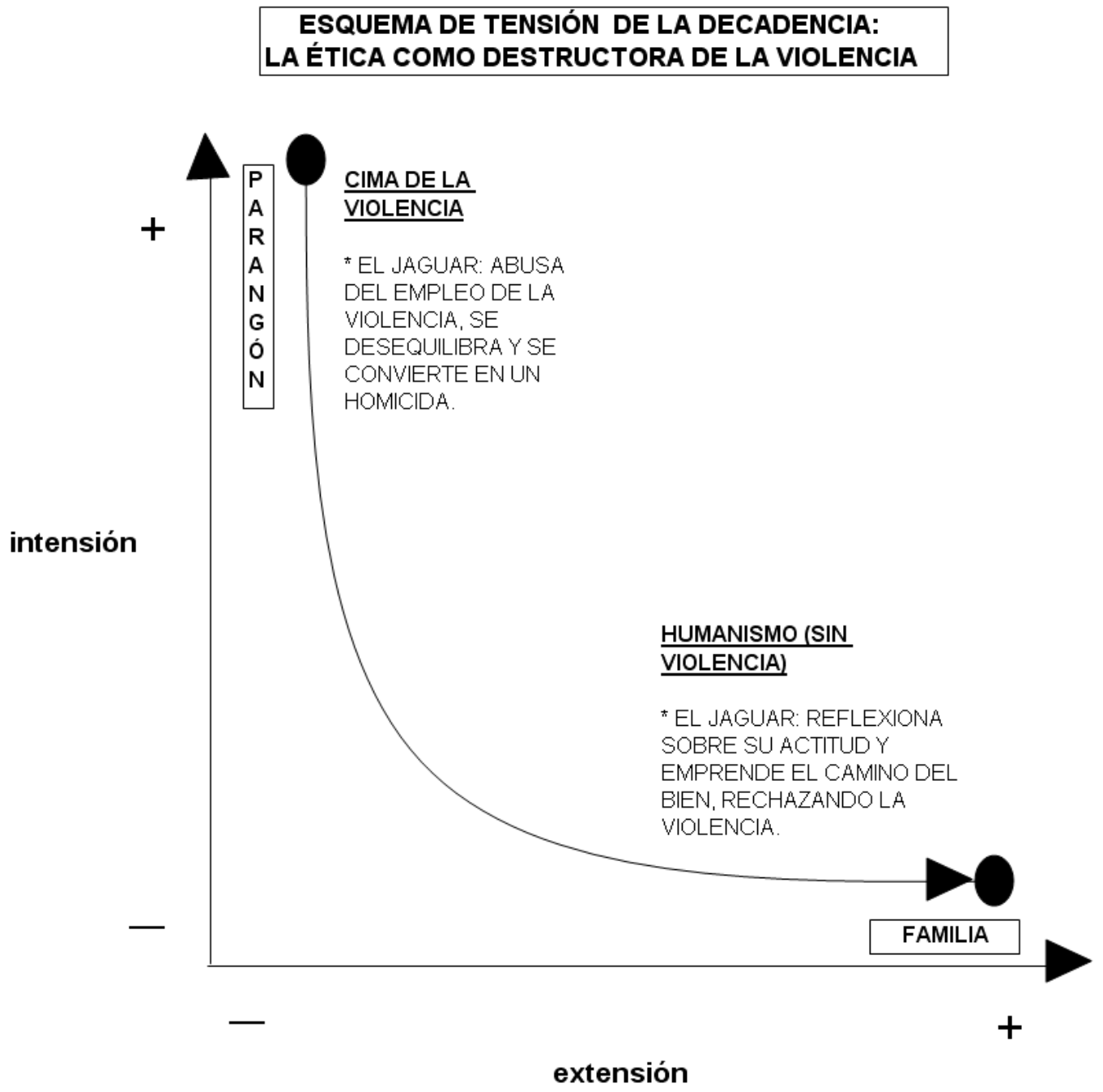

Este esquema es denominado el de la decadencia (Blanco, 2009, p. 44), el cual consiste en el debilitamiento de la intensidad, correlacionado con el despliegue de la extensión. Transita por las zonas o los estilos categoriales (Blanco, 2009, p. 22) del 
parangón (es el mejor ejemplar por presentar intensidad fuerte y extensión débil) al de la familia (posee una semejanza con la familia, al caracterizarse por su intensidad débil y su extensión fuerte). La intención principal de este recorrido es el de mostrar los valores del universo o los valores participativos, que promueven las ideologías democráticas e inclusivas, en todos los niveles de su manifestación: desde la política hasta la educación. De acuerdo con este esquema, la violencia se irá desintegrando con la adopción de posturas humanistas.

\section{Conclusiones}

Hay una necesidad de los personajes en querer destacar mediante la violencia; por tal motivo, deben deconstruir aquellas normas institucionales que se desarrollan en el Colegio Militar Leoncio Prado, a pesar de que las mismas autoridades son corruptas (enseñan y practican la agresión con la intención de infundir la disciplina). Para ello, el uso de la semiótica sirvió para observar y precisar esas modificaciones que poseen los militares, con la finalidad de hallar desbalances e inestabilidades en sus propias identidades.

\section{Referencias bibliográficas}

Álvarez, Ángeles. (2002). Guía para mujeres maltratadas (8. a ed.). La Mancha: Junta de Comunidades de Castilla.

Bajtín, Mijaíl. (1998). Estética de la creación verbal. México D. F.: Siglo Veintiuno Editores.

Blanco, Desiderio. (2003). Semiótica del texto fílmico. Lima: Fondo de Desarrollo Editorial, Universidad de Lima.

Blanco, Desiderio. (2009). Vigencia de la semiótica y otros ensayos. Lima: Fondo de Desarrollo Editorial, Universidad de Lima.

Doležel, Lubomír. (1999). Heterocósmica. Ficción y mundos posibles. Madrid: Arco/Libros.

Eco, Umberto. (2000). Tratado de semiótica general (5. ed.). Barcelona: Lumen. 


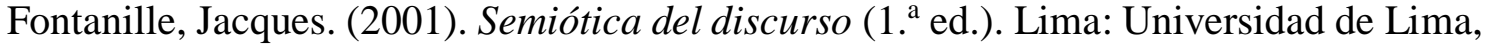
Fondo de Desarrollo Editorial.

Freud, Sigmund. (2004). Introducción al psicoanálisis. Madrid: Alianza Editorial.

Genette, Gérard. (1998). Nuevo discurso del relato. Madrid: Cátedra.

Hernández, Eva. (2001). Agresividad y relación entre iguales en el contexto de la enseñanza primaria. Estudio piloto (Trabajo de investigación para el programa de doctorado "Cooperación, Desarrollo Social y Democracia"). Universidad de Oviedo, Asturias, España.

Krishnamurti, Jiddu. (1991). Más allá de la violencia. Barcelona: Edhasa.

Lacan, Jacques. (1996). El seminario. Libro 17. El reverso del Psicoanálisis. Buenos Aires: Paidós.

Lacan, Jacques. (2006). El seminario. Libro 10. La angustia (1. ${ }^{\mathrm{a}}$ ed.). Buenos Aires: Paidós.

Landowski, Eric. (2009). Interacciones arriesgadas (1. ${ }^{\mathrm{a}}$ ed.). Lima: Fondo Editorial de la Universidad de Lima.

Perniola, Mario. (2008). Del sentir. Valencia: Pre-Textos.

Ricoeur, Paul. (1995). Tiempo y narración. Configuración del tiempo en el relato de ficción. Tomo II. Madrid: Siglo Veintiuno Editores.

Vargas Llosa, Mario. (2012). La ciudad y los perros. Edición conmemorativa del cincuentenario. Italia: Alfaguara, Real Academia Española.

Žižek, Slavoj. (2004). Violencia en acto. Conferencias en Buenos Aires. Buenos Aires: Paidós.

Žižek, Slavoj. (2008). Cómo leer a Lacan (1. a ed.). Buenos Aires: Paidós.

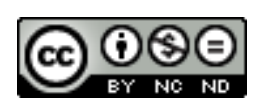

Esta obra está bajo una licencia de Creative Commons Reconocimiento-NoComercialSinObraDerivada 4.0 Internacional 